\title{
Analysis of the CHP Technological Innovation System in Iran using the Causal Layered Analysis (CLA)
}

Hossein Heirani

National Research Institute for Environmental and Agricultural Science and Technology Montpellier: Institut National de Recherche pour l'Agriculture l'Alimentation et l'Environnement Centre Occitanie-Montpellier

Naser Bagheri Moghaddam ( $\sim$ bagheri@nrisp.ac.ir)

National Research Institute for Science Policy

Mohammad Hassan Fazli

Iran University of Science and Technology

\section{Original article}

Keywords: Technological Innovation System, Causal Layered Analysis, Structural Equation Modelling, Technology Development, Cogeneration of Heat and Power

Posted Date: October 6th, 2020

DOI: https://doi.org/10.21203/rs.3.rs-81356/v1

License: (1) This work is licensed under a Creative Commons Attribution 4.0 International License. Read Full License 


\section{Abstract}

\section{Background:}

As many other countries, Iran has adopted policies consider energy technologies development. One of these technologies around which several national programs have launched is the Cogeneration of Heat and Power (CHP). Despite the variety of plans and actions in different governmental and non-governmental bodies, the fact is that the national targets have not been fulfilled as they were expected. Since the first step to make policies for technology development is recognizing the problems and bottlenecks hindering the development process, the main aim of this paper is to provide a model to analyze the failures of technology development process according to Technological Innovation System (TIS) approach. Besides, the CLA method has been used to decipher the profound and latent factors causing these problems.

\section{Results:}

By mixing up CLA and TIS approaches, this paper achieves a comprehensive model describing the causal relationship between multi-layered problems of technology development. Afterwards, by using structural equation modelling, the correlation amongst multi-layered problems was tested. While most studies have concentrated on the structural and functional problems of the TIS, the results of the model demonstrate a significant role of the discourses and visions. Although the structural problems have had the most significant effect on the functional problems, surprisingly, the second position is for the problems related to metaphors. This might be the most noticeable result of this research that the metaphoric and visionary factors can play a role as important as structures of the TIS.

\section{Conclusion:}

The results of the study indicate that the discursive and metaphoric factors have had the significant effect both directly on the failure of the CHP innovation system and indirectly through affecting structural elements. A notable policy suggestion is to change the discourse of centralized power generation and to make more effort regarding the energy efficiency in the society. Moreover, policies should create a positive and long-term vision for development of CHP plants.

\section{Introduction}

In contrast to the centralized systems of electricity, there are decentralized and independent generation methods including the Cogeneration of Heat and Power (CHP). Thermodynamically, this method involves cogeneration of two common forms of energy, namely electric and thermal, by using a primary source of energy. The benefits of concurrent generation systems include decentralized and independent generation of electricity and heat (Kelly and Pollitt, 2010), preventing the distribution and transmission losses in the grid, increasing the efficiency of energy conversion (Fumo et al., 2009), reducing fuel consumption and CO2 emission (Chicco and Mancarella, 2008).

Developing CHP technologies has received significant attention in Iran as a solution to improve energy efficiency, increase the power capacity, and reduce transmission loss and $\mathrm{CO} 2$ emission. This issue has been reflected in several national programs and master plans. For instance, $7000 \mathrm{MW}$ CHP plants have been targeted in the sixth national development program. Moreover, the Supreme Council for Science, Research and Technology of Iran has mentioned the CHP as one of the top ten technological priorities in the energy sector in Iran.

In spite of such emphasis at the highest level of decision making bodies of the country, and also the good fit of required resources and entities, the fact is that just around one tenth of targeted capacity has been realized so far. The question is "why the development process is not going well"?

We call the mentioned development process a "technological transition" which is defined as the replacement of technology in a socio-technical restructuring (Geels, 2002). In general, the management of the transition process can be divided into two phases: analysis and policymaking (Wieczorek and Hekkert, 2012). In the evolutionary approaches for transition management, both to analyze technology development and to make policies to manage it, recognizing the "system failures" is the first step (Edquist, 2010). 
There are number of evolutionary approaches to manage transition and consequently analyze system failures such as Innovation Systems (Carlsson and Stankiewicz, 1991), Transition Management (Rotmans et al., 2001) and Multi-level Perspective (Geels, 2002). Regarding the wide application of the TIS in the energy sector (Wieczorek et al., 2015) and also in the field of analyzing new technologies emergence and diffusion (Sandén et al., 2017), the authors put their focus on this approach. Another reason was the functional and structural perspective of the TIS (Suurs and Hekkert, 2009) which was in accordance with the condition under study.

The complementary approach selected to extract CHP system failures was the Causal Layered Analysis (CLA). A quick look at the $\mathrm{CHP}$ development trend in Iran reveals that there have been some bottlenecks "beyond" the functional and structural weaknesses. The main goal of the authors was to recognize these "hidden factors" which were less considered in previous studies. These factors at first seemed to be related to the contextual and social conditions. Along with a wide range of contextual elements, the CLA method considers the culture and worldview as realities behind the problems (Inayatullah, 1998). It also realizes different discourses beyond the visible problems as the "causes" which lead to a more in-depth understanding of the problem (Inayatullah, 2009).

According to the aforementioned issue, this paper aims at providing a model for extracting system failures with a systematic approach in order to analyze CHP development in Iran. The model is a combination of the TIS and the CLA approach with which policy makers would be able to achieve a comprehensive analysis.

\section{Background}

\subsection{Technological Innovation System (TIS)}

The Technological Innovation System approach can be known as the first approach used in the study of energy technologies (Jacobsson and Bergek, 2011), to the extent that it is known as a tool for analyzing success and failure of technological transitions in the energy sector (Wieczorek et al., 2015).

Bergek et al. define the TIS as a set of components, including technologies, actors, networks, and institutions, which are actively involved in developing a particular technology (Bergek et al., 2015). For such system, two basic pillars are considered: structural factors and functions. In this paper, the categorization of structural factors suggested by Wieczorek and Hekkert (2012) is considered as the base. In their work, four components of "Actors, Networks (interactions), Infrastructures and Institutions" are defined as the factors that shape the structure of the TIS. On the other hand, system functions focus on performance of the system components. These functions are considered to be the effective process factors for technological development. The categorization of seven functions introduced by Hekkert et al., 2007 and Bergek et al., 2008 has the most citation in the literature among other categorizations. This categorization include "Entrepreneurial activities, Knowledge development, Knowledge diffusion, Guidance of the search, Market formation, Mobilization of resources and Creation of legitimacy".

\subsection{Analysis of the Technological Innovation System}

In order to analyze the Technological Innovation System, there are several methods evolved over time. These methods are: outputbased analysis, based on functions, based on structural factors and based on the relationship between functions and structure. The outputs of each of these methods are the problems in the technology development process, or in other words, the "systemic failures" of the TIS.

Considering these different methods, the problems or failures extracted in related studies are mainly focused on the intra-system problems of the TIS. This fact can be viewed even in the structural-functional approach which is the latest and the most used approach (Markard et al., 2012, Truffer et al., 2009). This method considers structural factors as the cause of the functional problems, and does not pay much attention to factors outside the system. Moreover, contextual and social factors that can play a significant causative role in the emergence of problems in the transition process, especially in developing countries (Carlsson, 2006) have not been seriously addressed in the literature. The focus of this paper is to add extra system problems and to examine their effects on the structural and functional problems of the discussed TIS. 


\subsection{Contextual factors}

Each new Technological Innovation System is created with access to and use of its environmental and contextual resources, such as other industries (Jacobsson and Bergek, 2011). Hellsmark (2010) points out that the contextual factors in which a TIS is formed not only affect the available resources, but also the general direction of that system (Hellsmark, 2010). The contextual factors concept refers that technologies are developed differently in various environmental contexts. In addition, due to the instability and continuous changes of the contextual factors, challenges and opportunities for the development of new technologies would be better understood by analyzing the effects of these factors. Finally, introducing contextual factors into TIS-based analyses provides a more comprehensive framework for analyzing a particular technology development process, as well as other related peripheral conditions (Bergek et al., 2015).

Various attempts have been made to link different contextual elements, but in the paper of Bergek et al. (2015), for the first time, a comprehensive categorization of the contextual factors affecting the TIS has been presented as follows:

\section{Other TISs}

This refers to the connections between different Technological Innovation Systems, which include collaboration or competition of different technologies.

\section{Sector(s)}

This factor represents the institutions and infrastructures that exist jointly among different Technological Innovation Systems. The concept of system's interactions with its own sector is the same as the concept of socio-technical regimes suggested by Geels (2002).

\section{Geographical context}

Bergek et al. (2015) consider geographical factors as a set of political, social, cultural and legal factors that exist on the geographical boundaries of a given TIS. Therefore, a sort of overlap with other contextual factors may be perceived.

\section{Political context}

This factor also represents the general political conditions in the technology development environment. The relationship between the political environment and the Technological Innovation System could be called the main driver of long-term transition processes and the key factor in development of the TIS (Bergek et al., 2015).

As mentioned above, contextual factors, as factors that influence performance and structure of the TIS out of its boundaries, have been added to TIS analysis literature. In this paper, we have considered these factors as a component of the model for extracting and analyzing the problems of the defined TIS. The other causes of the TIS problems are extracted with the help of the Casual Layered Analysis method.

\subsection{Causal Layered Analysis (CLA)}

The Causal Layered Analysis, first proposed by Soheil Inayatullah, is a new theory in the field of futures studies. Other uses of this method are to identify social, organizational as well as policy making problems and to find their roots deeply(Inayatullah, 2009). This method considers four levels for analyzing social and organizational problems each of which represents a different angle from which the problem is viewed. 
Litany shows the first level of the layers which represents the obvious problems. At this level, trends, information, numbers, statistics and indicators could be seen. At the Social Systems level, social, economic, political and historical factors are addressed. Moreover, data of the previous level is quantitatively analyzed and structural relationships are investigated. Worldview (Discourse) layer, represents the worldview and dominant discourse that support the social structures of the second layer. At this level, contrary to the previous two levels, the assumptions considered defining the problems and analyzing them at level two are also questioned. Finally, Metaphor or Myth layer focuses on subconscious and emotional dimensions of individuals and societies. Inayatullah uses the term "collective archetypes" to describe this layer and defines it as "the unconscious and often emotive dimensions of the problem or the paradox" (Inayatullah, 2009).

To illustrate the structure of the layers in this method, the pyramid or iceberg forms are used. The reason is that the lower layers are deeper and the actors are less aware of them (Heinonen et al., 2017).

In this study, functional problems are considered as the main symptoms of problems in the TIS. The first step in analyzing these problems is structural analysis or identifying structural failures of the system. The next step of analysis mentioned in the literature is analyzing the contextual problems of the system that can be the cause of structural and functional problems. The innovation of this paper is adding another level to analyzing system problems, that is, the layers of the CLA method, which contains deeper causes than contextual problems. The following figure shows the relationship between different layers of the CLA and the TIS problems at different levels in the conceptual model of this paper.

\section{Method}

This research is a combination of quantitative and qualitative methods. The qualitative method is used for extracting the layered causes based on the focus group, and the quantitative method is used to test the model and finally examine the extracted relationships.

In order to collect the required data in the whole research process, the triangulation method has been used (Denzin, 2017). Accordingly, by collecting data from three sources of interview, observation and study of documents, the maximum accuracy of the collected data has been achieved. Also, an appropriate method has been used in each step for data analysis, which is described below.

In the first step, based on the literature of the TIS and the CLA, the theoretical model of the research was designed. In order to finalize the components and the indicators of the model, interviews were held with 12 experts in the field of innovation policy making, including Ph.D. students, professors and faculty members of the universities, so that the indicators were modified according to their comments.

The figure below shows the conceptual model and the extracted hypotheses. As can be seen, each of the hypotheses represents the effect of one causative layer on the others.

The second step was about recognizing the factors related to the first and the second levels of the CLA. Based on the structural functional analysis, after analyzing the relevant documents associated with the development problems of this technology, as well as semi-structured interviews, the existing problems at the level of functional, structural and contextual problems were discussed at meetings with experts in this field. Eventually, by gathering their comments through the thematic analysis method, the functional, structural and contextual problems for development of the CHP technology were extracted.

In the third step, after extracting topics of the problems related to the third and fourth layers of the CLA in semi-structured interviews and a focus group meeting, the experts' comment regarding the most important bottlenecks hindering CHP development were recognized. 
Given that the standard number of focus groups has been determined to be 8 to 10 people (Morgan, 1997), totally 9 people were present in the focus groups. Also, the reason for selecting the thematic analysis method for summing up the results of the focus group was that more attention is paid to the details and texture of the data. Furthermore, unlike the content analysis, the analysis unit is more than one word or term here. In fact, the thematic analysis goes beyond the mere counting of terms and phrases and emphasizes the explanation and interpretation of implicit concepts (Guest et al., 2011).

There are several ways to categorize the themes. In this paper, the basis for categorization of the themes is based on Ryan and Bernard's method containing initial and final themes (Ryan and Bernard, 2000). The reason is that conducting interviews and holding focus group meetings were based on the layers of the model and actually determined the overall framework of the themes or in other words the initial themes. Afterwards, comments and general propositions were interpreted and categorized into the final themes and formed the eventual problems.

Accordingly, 104 initial themes were extracted from the total interviews and the focus group, and at the final step, 52 final phrases were introduced as problems of the Technological Innovation System of the CHP in Iran. The final themes that are in fact the final problems in each layer are presented in the next section of the paper.

After extracting the problems, a questionnaires was sent to the experts in order to assess the impact of the different problems on the CHP development in Iran. In this questionnaire, based on the 5-point Likert spectrum, the severity of the aforementioned problems was also asked.

The tool for analyzing and measuring the hypotheses was the Structural Equation Modeling (SEM). The purpose was to combine quantitative and qualitative methods to increase the richness of the analysis. In fact, as pointed out by Inayatollah, in academic research, it is necessary to examine the extracted factors in each layer quantitatively in order to determine, firstly, the importance of each factor and, secondly, the intensity of the effects of each factor on the other layers (Inayatullah, 2009).

Moreover, considering the insufficiency of the sample size due to limitation of the experts in the discussed area, to test the hypotheses of the research, Confirmatory Factor Analysis (CFA) was used. In addition, the Partial Least Squares (PLS) method was applied by using the SmartPLS software version 2. This method is used when the sample size is small or the distribution of variables is not normal (Hair et al., 1998). The table in Appendix.1 of the paper shows the characteristics of the statistical sample in each of the steps.

\section{The Recognized Problems In The Five Layers Of The Research Model}

Based on the explanations given in the previous section, through the focus group meeting the total problems of the CHP development were obtained.

Regarding the functional problems, the most important issue raised by the members was failure to form a market for this technology. Indeed, a good number of companies were applicant to install and construct CHP plants at first, but in recent years, this trend has been declining and is about to stop. Another problem is the lack of technical knowledge within the country. The dependence on foreign knowledge and equipment, in particular the generators, slowed down the development of the CHP, especially during the sanctions.

Turning to the structural causes of the mentioned problems, the issue agreed upon by all members was the problems of interactions, especially with the national gas company and in general the oil and gas sector. Problems such as the lack of common regulations, the lack of integration of the licensing process, and in general, the lack of a unit management for the energy sector in the country, were the main problems raised in this layer. Another point was the lack of smart network infrastructures in the country as a prerequisite for the development of distributed generation.

In the layer of the contextual problems, the lack of the required coordination and cooperation between the gas sector and the Tavanir Company (The national power company), as the complementary innovation system, was the main reason for creating structural and functional problems. In fact, given that the inputs and outputs of the cogeneration plants consist of gas and heat, the power sector cannot plan and make policy on this technology alone. Here, this lack of integrity leads to problems in coordination and alignment of policies, which is one of the main reasons for insufficient development of the CHP. One of the

Page 6/15 
indicators of this lack of coordination is the price of gas. The price of gas entering CHP plants is a decisive factor in the unjustifiability of this technology. Due to low gas price in the country, the heat generated from CHP is not economically efficient and cannot compete with the alternative resource, that is, gas.

Different topics were expressed in the discourse layer. The aforementioned points can be summarized in domination of the renewable energy discourse as well as the discourse for centralized electricity production. In other words, the focus on development of renewable energies in Iran is more than that of other distributed generation methods, such as cogeneration. Members of the focus group argued that the reason for this issue is the existence of a specific custodian for renewable energies as well as the personal interest of managers in this area. This domination of the renewable energies discourse is so that even the projected budgets for energy efficiency, for example, the percentage considered in electricity bills, are mainly spent for development of renewable plants. Another point agreed upon by the members was the deep-rooted idea of centralized generation in the country. This centralized and controlled production, both in the electricity and in the other sectors, has been the driving force behind decisions and policies.

Finally, in the last layer, some members identified terms like "every man for himself" or "when things got to the worst they will mend" as dominant mentality of Iranians. These terms represent individualist thinking (departmentalism in management) as well as short-term vision and failure to prevent crises. Another point raised as a problem of this layer was the lack of a clear perspective for distributed generation and focus on renewable energies as a future perspective for Iran's power industry.

The table mentioned in the Appendix.2 displays the final problems extracted from the focus group, which were identified as the base for the proposed model.

\section{Results}

As explained in the previous section, severity of the extracted problems was questioned by experts in the form of a five-point Likert questionnaire. In this questionnaire, number 1 indicated very weak severity of the problem and number 5 indicated the existence of a serious problem. The following table shows the dispersion indexes for the layered problems based on the responses received. 
Table 1

Indexes of dispersion

\begin{tabular}{|c|c|c|c|c|c|c|c|c|c|}
\hline \multirow[t]{2}{*}{$\begin{array}{l}\text { Main } \\
\text { problems }\end{array}$} & \multirow[t]{2}{*}{ Variable } & \multirow[t]{2}{*}{ Number } & \multirow[t]{2}{*}{ Mean } & \multirow[t]{2}{*}{ Median } & \multirow[t]{2}{*}{$\begin{array}{l}\text { Standard } \\
\text { deviation }\end{array}$} & \multicolumn{2}{|c|}{$\begin{array}{l}\text { Indicators of } \\
\text { normality }\end{array}$} & \multirow[t]{2}{*}{ Minimum } & \multirow[t]{2}{*}{ Maximum } \\
\hline & & & & & & Skewness & Kurtosis & & \\
\hline \multirow{7}{*}{$\begin{array}{l}\text { Functions } \\
\text { of TIS }\end{array}$} & Entrepreneurship & 63 & 4.079 & 4 & 0.752 & -0.66 & -0.149 & 2 & 5 \\
\hline & $\begin{array}{l}\text { Knowledge } \\
\text { development }\end{array}$ & 63 & 3.915 & 4 & 0.75 & -0.242 & -0.495 & 2 & 5 \\
\hline & $\begin{array}{l}\text { Knowledge } \\
\text { diffusion }\end{array}$ & 63 & 3.926 & 4 & 0.668 & -0.628 & 1.088 & 2 & 5 \\
\hline & $\begin{array}{l}\text { Guidance of the } \\
\text { research }\end{array}$ & 63 & 4.206 & 4 & 0.676 & -0.558 & -0.474 & 2.5 & 5 \\
\hline & $\begin{array}{l}\text { Market } \\
\text { formation }\end{array}$ & 63 & 4.026 & 4 & 0.675 & -0.268 & -0.711 & 2.667 & 5 \\
\hline & $\begin{array}{l}\text { Mobilization of } \\
\text { resources }\end{array}$ & 63 & 4.101 & 4 & 0.679 & -0.555 & -0.433 & 2.333 & 5 \\
\hline & $\begin{array}{l}\text { Creation of } \\
\text { legitimacy }\end{array}$ & 63 & 4.008 & 4 & 0.698 & -0.396 & -0.552 & 2.5 & 5 \\
\hline \multirow{4}{*}{$\begin{array}{l}\text { Structural } \\
\text { problems }\end{array}$} & Institutions & 63 & 4.175 & 4 & 0.741 & -0.723 & -0.016 & 2 & 5 \\
\hline & Interactions & 63 & 3.968 & 4 & 0.756 & -0.641 & 0.55 & 1.5 & 5 \\
\hline & Actors & 63 & 4.074 & 4 & 0.742 & -0.489 & -0.399 & 2 & 5 \\
\hline & Infrastructures & 63 & 4.032 & 4 & 0.764 & -0.686 & -0.122 & 2 & 5 \\
\hline \multirow{4}{*}{$\begin{array}{l}\text { Contextual } \\
\text { problems }\end{array}$} & Political & 63 & 4.095 & 4 & 0.767 & $-0 / 581$ & -0.5 & 2.5 & 5 \\
\hline & Geographical & 63 & 3.77 & 4 & 0.906 & -0.587 & 0.409 & 1 & 5 \\
\hline & $\begin{array}{l}\text { Other innovation } \\
\text { systems }\end{array}$ & 63 & 3.884 & 4 & 0.683 & -0.148 & -0.871 & 2.333 & 5 \\
\hline & Sector & 63 & 4.214 & 4 & 0.646 & -0.719 & 0.235 & 2.5 & 5 \\
\hline \multirow{3}{*}{$\begin{array}{l}\text { Worldview } \\
\text { problems }\end{array}$} & Discourses & 63 & 4.201 & 4.333 & 0.725 & -0.966 & 0.639 & 2 & 5 \\
\hline & $\begin{array}{l}\text { Values and } \\
\text { norms }\end{array}$ & 63 & 3.603 & 3.5 & 0.794 & -0.301 & 0.502 & 1 & 5 \\
\hline & $\begin{array}{l}\text { Dominant } \\
\text { culture }\end{array}$ & 63 & 4.497 & 5 & 0.759 & -1.625 & 1.893 & 2 & 5 \\
\hline \multirow[t]{3}{*}{ Metaphors } & Visions & 63 & 3.968 & 4 & 0.756 & -0.236 & -0.601 & 2 & 5 \\
\hline & Myths & 63 & 3.825 & 4 & 0.789 & -0.058 & -0.865 & 2 & 5 \\
\hline & Metaphors & $63 \square$ & 3.802 & 4 & 0.854 & -0.592 & 0.55 & 1 & 5 \\
\hline
\end{tabular}

According to the results of the table, all skewness values are between 2 and -2 , and also the kurtosis values are in the range of 5 to -5 . Therefore, the data distribution is symmetric and normal.

\subsection{Evaluation of Validity and Reliability}

In order to measure the validity, two indicators of Factor Loading and Average Variance Extracted (EVA) have been considered. Also, to examine the reliability of the research method, the Cronbach's alpha and composite reliability have been used and their results are presented below. 
Figure 3 illustrates the Structural Equation Modeling of the Technological Innovation System problems for CHP in the mode of estimating the standard coefficients and absolute values of significant coefficients (t-value).

According to this model, the path coefficient is significant at the $95 \%$ confidence level, since the value of the $t$ statistic is greater than 1.96. As shown in the Appendix.3, all factor loads are greater than 0.4 and are significant at the $95 \%$ confidence level.

Therefore, consistency of the questionnaire is valid to measure the concepts at this stage. Also, all path coefficients have a critical factor out of the range $(-1.96,1.96))$, which confirms the effect of the main variables on each other.

Other validity and reliability indicators of the model are shown in the Appendix 3 . By examining the AVE, the convergent validity is also confirmed. Reliability indicators including Cronbach's alpha and composite reliability are higher than 0.7 and 0.6 , respectively. Therefore, the reliability of the questionnaire is confirmed.

\subsection{Testing the hypotheses of the theoretical model}

The results of the path coefficients, t-value statistic, and also the significant rejection or acceptance of the hypotheses for the model are presented in the following table, which ultimately indicates confirmation of the hypotheses.

Table 2

Results of the path coefficients and t-value statistic

\begin{tabular}{|c|c|c|c|c|c|}
\hline Hypothesis & $\begin{array}{l}\text { Path } \\
\text { coefficient ( } \\
\beta)\end{array}$ & $\begin{array}{l}\text { Critical } \\
\text { ratio }(t)\end{array}$ & $\begin{array}{l}\text { Coefficient of } \\
\text { Determination }\left(R^{2}\right)\end{array}$ & $\begin{array}{l}\text { Confirmation or rejection } \\
\text { of hypothesis }\end{array}$ & $\begin{array}{l}\text { Effect } \\
\text { direction }\end{array}$ \\
\hline $\begin{array}{l}\text { Structural factors -> } \\
\text { Functions of TIS }\end{array}$ & 0.333 & 4.589 & \multirow[t]{4}{*}{0.828} & Confirmed & + \\
\hline $\begin{array}{l}\text { Contextual factors -> } \\
\text { Functions of TIS }\end{array}$ & 0.130 & 2.113 & & Confirmed & + \\
\hline $\begin{array}{l}\text { Discourses -> Functions of } \\
\text { TIS }\end{array}$ & 0.199 & 3.380 & & Confirmed & + \\
\hline $\begin{array}{l}\text { Metaphors -> Functions of } \\
\text { TIS }\end{array}$ & 0.326 & 5.140 & & Confirmed & + \\
\hline $\begin{array}{l}\text { Contextual factors -> } \\
\text { Structural factors }\end{array}$ & 0.418 & 7.893 & \multirow[t]{3}{*}{0.786} & Confirmed & + \\
\hline $\begin{array}{l}\text { Metaphors -> Structural } \\
\text { factors }\end{array}$ & 0.165 & 3.278 & & Confirmed & + \\
\hline $\begin{array}{l}\text { Discourses -> Structural } \\
\text { factors }\end{array}$ & 0.380 & 6.005 & & Confirmed & + \\
\hline $\begin{array}{l}\text { Metaphors -> Contextual } \\
\text { factors }\end{array}$ & 0.541 & 7.672 & \multirow[t]{2}{*}{0.667} & Confirmed & + \\
\hline $\begin{array}{l}\text { Discourses -> Contextual } \\
\text { factors }\end{array}$ & 0.325 & 4.538 & & Confirmed & + \\
\hline Metaphors $->$ Discourses & 0.764 & 27.017 & 0.584 & Confirmed & + \\
\hline
\end{tabular}

As can be seen, the structural problems have had the most significant effect on the functional problems. Surprisingly, the second position is for the problems related to metaphors. This might be the most noticeable result of this research that the metaphoric and visionary factors can play a role as important as structures of the TIS.

When it comes to the structural problems, context will be more effective. As demonstrated in the results, the contextual items have the most notable effect on the structure of the TIS. The key note is that the contextual problems are affected by the metaphoric barriers significantly. Here, one can result that, metaphoric problems are playing a crucial role on the structural problems of the TIS 
indirectly. Hence, the metaphoric bottlenecks represent a significant effect directly on the functional problems, and indirectly on the structural problems of the TIS.

The greatest path coefficient goes for the effect of metaphors on the discourses that was more or less expected by the authors, since discourses are often formed in regards to common visions. The details of how different problems have hindered the CHP development are discussed in the next part.

\section{Discussion And Conclusion}

This paper was conducted with the aim of analyzing the problems of technology development in the energy sector of Iran, focusing on the Cogeneration of Heat and Power (CHP), and using the TIS approach. Based on this approach, at first, the functional problems of the system were recognized and the structural factors were identified as the causes of each functional problem. Accordingly, two improvable points in this method were considered by the researchers. First, the contextual factors of the Technological Innovation System were used to analyze the external and environmental factors affecting the system. In the second stage, the Causal Layered Analysis was added to the framework to recognize the problems in deeper causative layers.

Combination of the two mentioned analytical frameworks, formed the conceptual model of the CHP innovation system causative analysis which is in fact the model of the relationship between various problems hindering the technology development in the energy sector of the country.

In the next stages, based on interview analysis and focus group, the functional, structural and contextual problems as well as the problems of the third and fourth layers of the CLA method were identified and the results were tested through the structural equation modelling.

Totally, the results of the conceptual model test show that extra system problems, including problems related to the contextual factors, discursive problems and metaphoric problems, have had a significant effect on failure of development of the CHP technology in Iran. This result is consistent with the views of Weizork and Heckert (2012) who point out that despite the widespread use of structural analysis to analyze the innovation system problems, due to the strong dependence of the structural factors on indigenous characteristics, policymakers cannot easily determine the structures of successful innovation systems as the indicator. A notable example related to the studied technology is the lack of a clear and specific vision for the development of $\mathrm{CHP}$ technologies, as well as the dominant vision of renewable energies development, which has had a similar effect on the system functions in comparison with the structural factors. Indeed, an extra system problem, such as the vision of the energy sector of a country, can have a significant effect on the structural factors and the functions of an innovation system.

The results of factor analysis of the conceptual model briefly demonstrate:

- In the field of the functional problems, the formation of technology market is more intense; failure to establish and enforce the efficiency standards for power plants in an integrated manner and the lack of demand articulation policies to stimulate the technology development in the country are the most important functional problems.

- When it comes to structure, institutions problems and in particular, the lack of required standards and regulations for connecting small-scale CHP plants to the national grid display the highest intensity.

- In terms of the contextual problems, the most important problems are those related to other TISs, and in particular the lack of gas sector's planning for purchasing the output heat of the CHP plants as well as the low and unbalanced price of natural gas.

- In the field of the discourse and worldview problems, the most important issue is related to the dominant discourses, and in particular the dominant discourse of the country's electricity sector on power generation instead of efficiency and environmental issues, as well as the dominance of centralized generation discourse and traditional generation methods. This issue is of greater intensity.

- In the field of the metaphoric and visionary problems, the lack of a clear and decisive vision for the CHP development and the dominant vision on development of the renewable power plants in spite of having a higher efficiency is of the greatest intensity. 
Finally, the summary of the model's path coefficient analysis indicates that the discursive and metaphoric factors have had the significant effect both directly on the failure of the CHP innovation system and indirectly through affecting structural elements. This is consistent with Wieczorek et al. (2015) since they emphasis on the role of contextual and local norms and institutes on the innovation system, especially in developing countries (Wieczorek et al., 2015). The role of the fourth layer problems, the existing visions, in both functional problems and the problems of other layers is significant and can be considered as an important achievement of this study, since attention to these factors has been neglected in analyzing the problems of the Technological Innovation System.

\section{Policy Suggestions}

Given the results of the problem identification phase, policy solutions can be provided to eliminate or reduce problems at different levels. For overcoming structural problems, for example, it is possible to develop and enforce various standards regarding the efficiency of power plants and the connection of CHP plants to the power distribution grid.

Regarding the contextual problems, modification of gas price and coordination between programs and policies of the electricity sector and the gas sector of the country are recommended.

Another suggestion is to change the discourse of centralized power generation and to make more effort regarding the energy efficiency in the society. Moreover, policies should create a positive and long-term vision for development of CHP plants.

\section{List Of Abbreviations}

CHP: Cogeneration of Heat and Power

TIS: Technological Innovation System

CLA: Causal Layered Analysis

\section{Availability Of Data And Materials}

Data and additional materials are available on request.

\section{Declarations}

\subsection{Ethics approval and consent to participate}

Not applicable.

\subsection{Consent for publication}

All authors have given their consent for this paper to be considered for publication.

\subsection{Competing interests}

The authors declare that they have no competing interests.

\subsection{Funding}

Not applicable.

\subsection{Authors' contributions}


The main idea of the paper came from N. B. Moghaddam. H. Heirani organized the research scheme and M. H. Fazli contributed in determining research method. The paper was written by M. H. Fazli and H. Heirani jointly, under N. B. Moghaddam's supervision. H. Heirani gathered the background and literature review and M. H. Fazli was in charge of writing other sections. The main research problem was designed by N. B. Mogahddam. All the authors read and approved the final manuscript and made some modofications.

\subsection{Acknowledgements}

The authors are grateful to the National Research Institute for Science Policy for providing infrastructures for the authors to conduct their research. The authors also acknowledge the Niroo Research Institute and Ministry of Power for their support through the access to experts and holding the interviews and focus group session.

\section{References}

BERGEK, A., HEKKERT, M., JACOBSSON, S., MARKARD, J., SANDÉN, B. \& TRUFFER, B. 2015. Technological innovation systems in contexts: Conceptualizing contextual structures and interaction dynamics. Environmental Innovation and Societal Transitions, 16, 51-64.

CARLSSON, B. 2006. Internationalization of innovation systems: A survey of the literature. Research policy, 35, 56-67.

CARLSSON, B. \& STANKIEWICZ, R. 1991. On the nature, function and composition of technological systems. Journal of evolutionary economics, 1, 93-118.

DENZIN, N. K. 2017. Sociological methods: A sourcebook, Routledge.

EDQUIST, C. 2010. Systems of innovation perspectives and challenges. African Journal of Science, Technology, Innovation and Development, 2, 14-45.

GEELS, F. W. 2002. Technological transitions as evolutionary reconfiguration processes: a multi-level perspective and a case-study. Research policy, 31, 1257-1274.

GUEST, G., MACQUEEN, K. M. \& NAMEY, E. E. 2011. Applied thematic analysis, sage.

HAIR, J., ANDERSON, R., TATHAM, R. \& BLACK, W. 1998. Factorial analysis. Multivariate Data Analysis. Fifth edition. New Jersey: Prentice Hall.

HEINONEN, S., MINKKINEN, M., KARJALAINEN, J. \& INAYATULLAH, S. 2017. Testing transformative energy scenarios through causal layered analysis gaming. Technological Forecasting and Social Change, 124, 101-113.

HELLSMARK, H. 2010. Unfolding the formative phase of gasified biomass in the European Union: The role of system builders in realising the potential of second-generation transportation fuels from biomass, Chalmers University of Technology.

INAYATULLAH, S. 1998. Causal layered analysis: Poststructuralism as method. Futures, 30, 815-829.

INAYATULLAH, S. 2009. Causal layered analysis: An integrative and transformative theory and method. Futures Research Methodology, Version, 3.

JACOBSSON, S. \& BERGEK, A. 2011. Innovation system analyses and sustainability transitions: Contributions and suggestions for research. Environmental Innovation and Societal Transitions, 1, 41-57.

MARKARD, J., RAVEN, R. \& TRUFFER, B. 2012. Sustainability transitions: An emerging field of research and its prospects. Research policy, 41, 955-967.

MORGAN, D. 1997. The focus group guidebook, Sage publications.

Page $12 / 15$ 
ROTMANS, J., KEMP, R. \& VAN ASSELT, M. 2001. More evolution than revolution: transition management in public policy. foresight, 3, 15-31.

RYAN, G. W. \& BERNARD, H. R. 2000. Data management and analysis methods.

SANDÉN, B., HEKKERT, M. \& NEGRO, S. Improving the rigour of the Technological Innovation Systems framework: towards a TIS model. 2017.

SUURS, R. A. \& HEKKERT, M. P. 2009. Cumulative causation in the formation of a technological innovation system: The case of biofuels in the Netherlands. Technological Forecasting and Social Change, 76, 1003-1020.

TRUFFER, B., ROHRACHER, H. \& MARKARD, J. 2009. The Analysis of Institutions in Technological Innovation Systems-A conceptual framework applied to biogas development in Austria. Copenhagen: Copenhagen Business School, 7.

WIECZOREK, A. J. \& HEKKERT, M. P. 2012. Systemic instruments for systemic innovation problems: A framework for policy makers and innovation scholars. Science and Public Policy, 39, 74-87.

WIECZOREK, A. J., HEKKERT, M. P., COENEN, L. \& HARMSEN, R. 2015. Broadening the national focus in technological innovation system analysis: The case of offshore wind. Environmental Innovation and Societal Transitions, 14, 128-148.

\section{Figures}

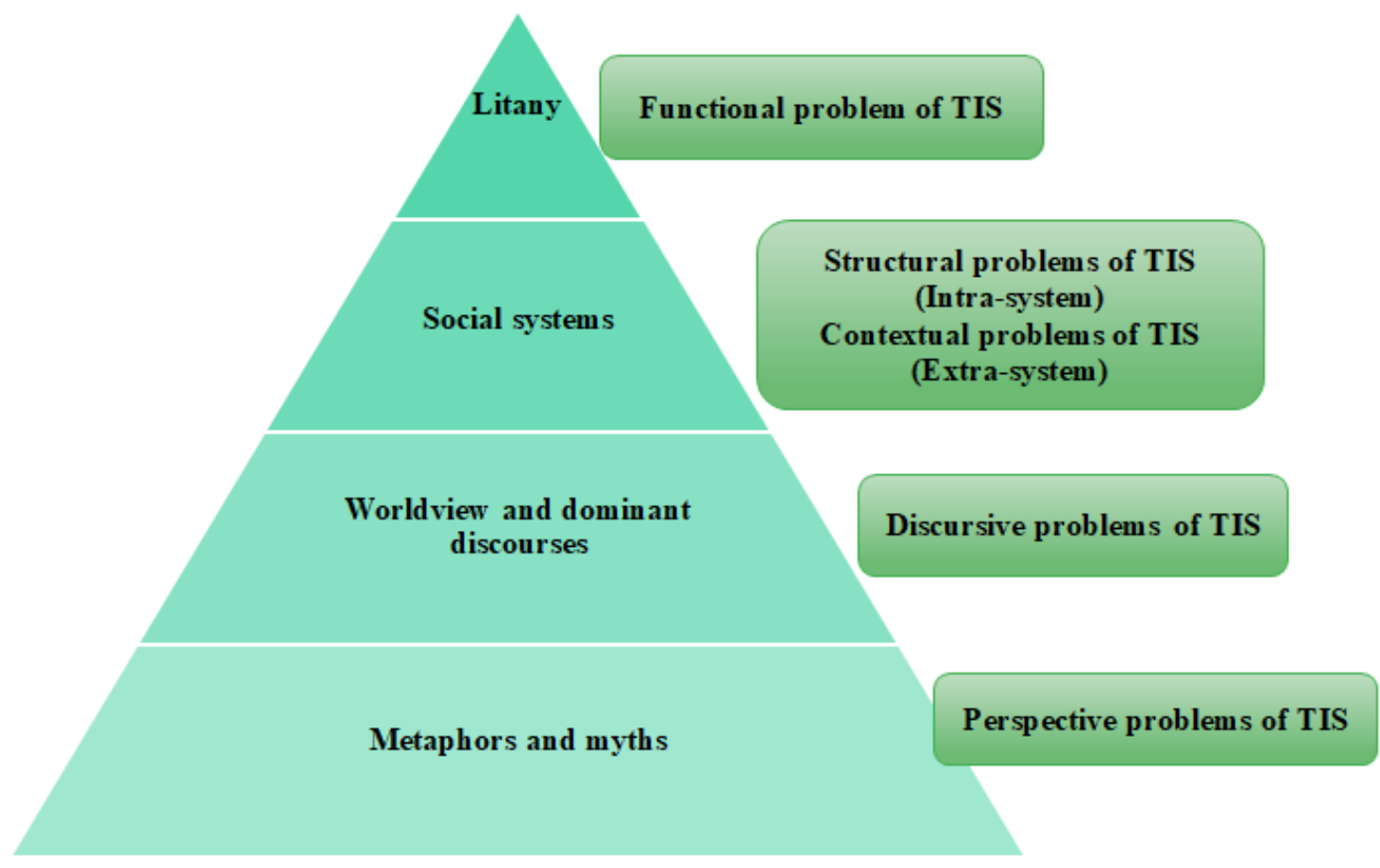

Figure 1

The relation of CLA and TIS 


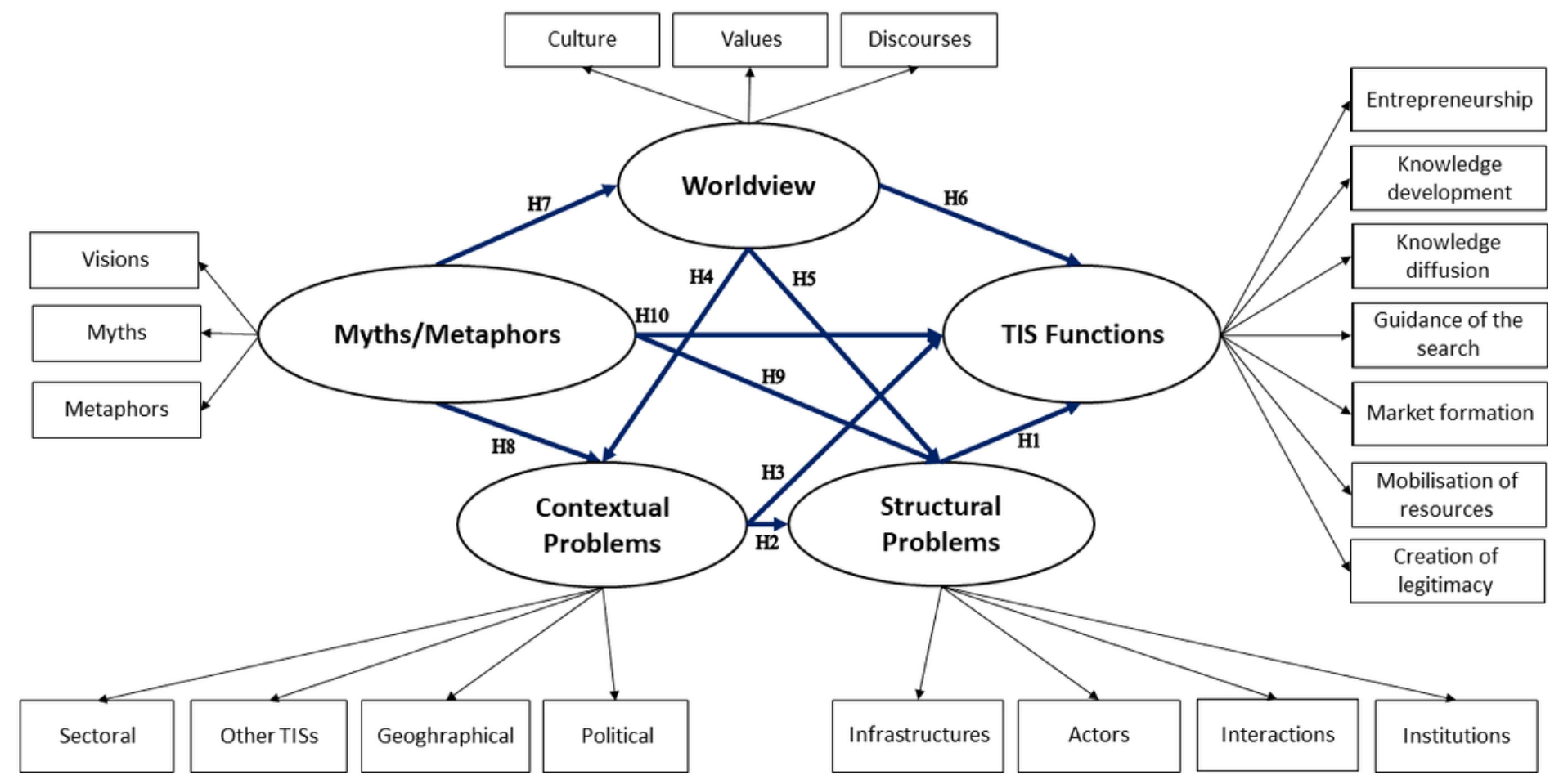

Figure 2

Conceptual model of the research 


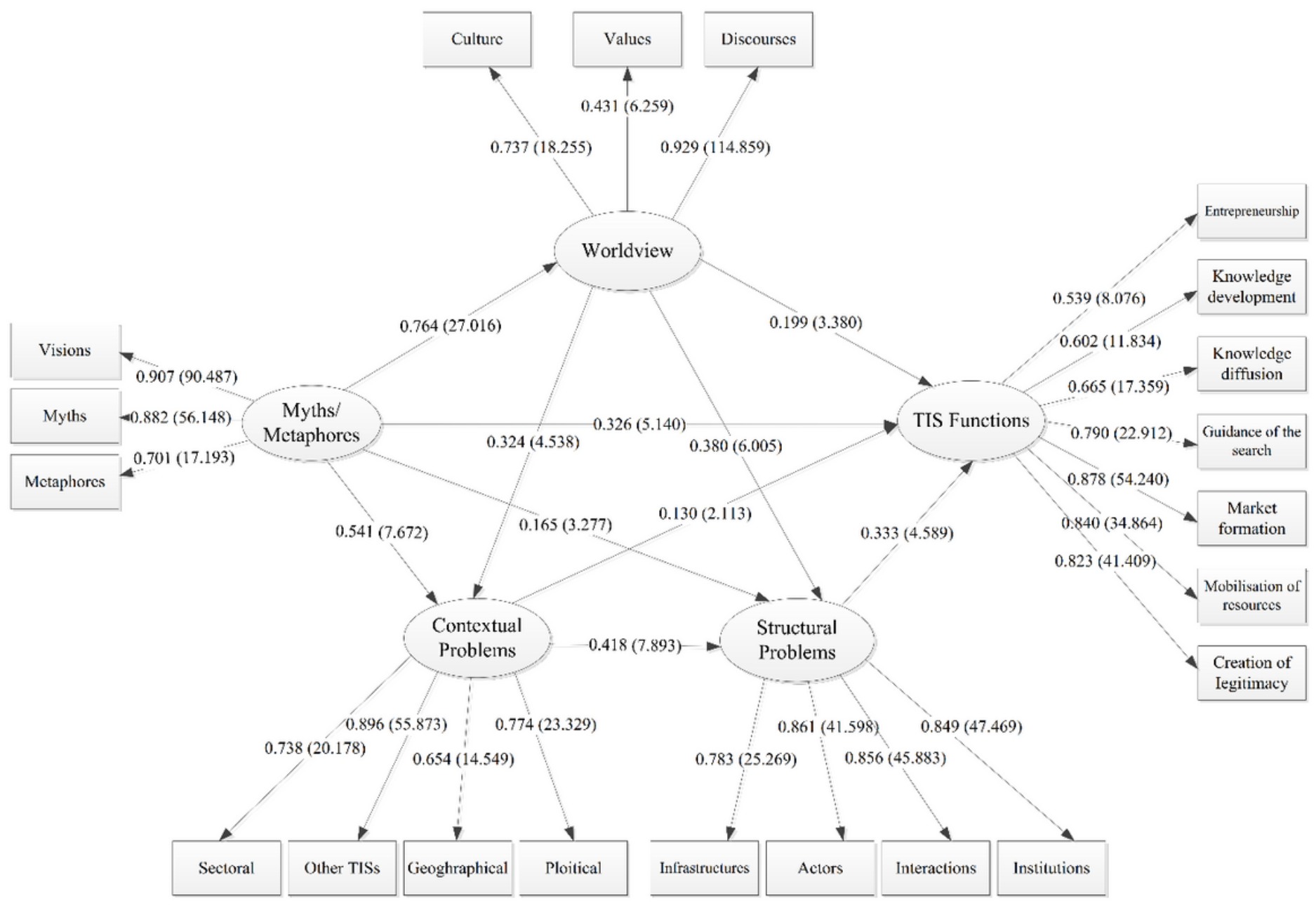

Figure 3

Structural Equation Model

\section{Supplementary Files}

This is a list of supplementary files associated with this preprint. Click to download.

- Appendix.docx 